\title{
(2) OPEN ACCESS \\ Prevalence and clinical implications of persistent or exertional cardiopulmonary symptoms following SARS-CoV-2 infection in 3597 collegiate athletes: a study from the Outcomes Registry for Cardiac Conditions in Athletes (ORCCA)
}

\author{
Bradley J Petek (1), ${ }^{1}$ Nathaniel Moulson, ${ }^{1,2}$ Aaron L Baggish, ${ }^{2}$ \\ Stephanie A Kliethermes (1), ${ }^{3}$ Manesh R Patel, ${ }^{4}$ Timothy W Churchill, ${ }^{2}$ \\ Kimberly G Harmon ${ }^{\circ},{ }^{5}$ Jonathan A Drezner ${ }^{\circ},{ }^{5}$ For the ORCCA Investigators
}

- Additional supplemental material is published online only. To view, please visit the journal online (http://dx.doi. org/10.1136/bjsports-2021104644)

For numbered affiliations see end of article.

\section{Correspondence to}

Professor Jonathan A Drezner, Department of Family Medicine, Center for Sports Cardiology, University of Washington, Seattle, WA 98195, USA; jdrezner@uw.edu

BJP and NM contributed equally.

KGH and JAD contributed equally.

BJP and NM are joint first authors.

KGH and JAD are joint senior authors.

Accepted 20 October 2021

Check for updates

(c) Author(s) (or their employer(s)) 2021. Re-use permitted under CC BY-NC. No commercial re-use. See rights and permissions. Published by BMJ.

\section{To cite: Petek BJ,}

Moulson N, Baggish AL, et al. Br I Sports Med Epub ahead of print: [please include Day Month Year]. doi:10.1136/ bisports-2021-104644

\section{ABSTRACT}

Objective To assess the prevalence and clinical implications of persistent or exertional cardiopulmonary symptoms in young competitive athletes following SARSCoV-2 infection.

Methods This observational cohort study from the Outcomes Registry for Cardiac Conditions in Athletes included 3597 US collegiate athletes after SARS-CoV-2 infection. Clinical characteristics, advanced diagnostic testing and SARS-CoV-2-associated sequelae were compared between athletes with persistent symptoms $>3$ weeks, exertional symptoms on return to exercise and those without persistent or exertional symptoms.

Results Among 3597 athletes (mean age 20 years (SD, 1 year), 34\% female), data on persistent and exertional symptoms were reported in 3529 and 3393 athletes, respectively. Persistent symptoms $>3$ weeks were present in $44 / 3529(1.2 \%)$ athletes with 2/3529 $(0.06 \%)$ reporting symptoms $>12$ weeks. Exertional cardiopulmonary symptoms were present in 137/3393 $(4.0 \%)$ athletes. Clinical evaluation and diagnostic testing led to the diagnosis of SARS-CoV-2-associated sequelae in 12/137 (8.8\%) athletes with exertional symptoms (five cardiac involvement, two pneumonia, two inappropriate sinus tachycardia, two postural orthostatic tachycardia syndrome and one pleural effusion). No SARS-CoV-2-associated sequelae were identified in athletes with isolated persistent symptoms. Of athletes with chest pain on return to exercise who underwent cardiac MRI (CMR), 5/24 (20.8\%) had probable or definite cardiac involvement. In contrast, no athlete with exertional symptoms without chest pain who underwent $\mathrm{CMR}(0 / 20)$ was diagnosed with probable or definite SARS-CoV-2 cardiac involvement. Conclusion Collegiate athletes with SARS-CoV-2 infection have a low prevalence of persistent or exertional symptoms on return to exercise. Exertional cardiopulmonary symptoms, specifically chest pain, warrant a comprehensive evaluation.

\section{INTRODUCTION}

SARS-CoV-2 infection may result in persistent symptoms or prolonged recovery in hospitalised patients suffering severe disease and in nonhospitalised patients with mild to moderate illness. ${ }^{1}$
Symptoms lasting beyond 3-4 weeks are considered prolonged, and those lasting greater than 12 weeks have been termed 'chronic COVID-19' or 'postacute COVID-19 syndrome' (PACS). ${ }^{2}$ PACS is a diagnosis of exclusion, and other possible disease sequalae, including inflammatory heart disease or pulmonary embolism $(\mathrm{PE})$, require consideration in the appropriate clinical context. ${ }^{3-5}$

The proportion of young competitive athletes with severe SARS-CoV-2 infection, defined by a requirement for hospitalisation, is low $(0.2 \%){ }^{3}$ The prevalence of prolonged symptoms in adult non-athletes that do not require hospitalisation is reported to be up to $47 \% .^{6-8}$ Prolonged symptoms in this population are associated with the presence of $\geq 1$ comorbidity and $\geq 6$ separate symptoms during the acute illness. ${ }^{8}$ To date, no studies exist on the prevalence of prolonged symptoms in young competitive athletes. Additionally, a unique and potentially concerning clinical scenario in the athlete population is the presence of exertional symptoms on return to exercise which could reflect dangerous, previously undiagnosed underlying cardiopulmonary pathology. While the risk of SARS-CoV-2 cardiac involvement in young and otherwise healthy athletes appears relatively rare in large cohort studies $(0.5 \%-3.0 \%)$, the presence of cardiopulmonary symptoms, including chest pain and dyspnoea, was identified as an independent predictor of SARS-CoV-2 cardiac involvement. ${ }^{3-5}$

The Outcomes Registry for Cardiac Conditions in Athletes ('ORCCA Registry') was designed to collect data documenting symptoms, diagnostic testing, cardiac and non-cardiac diagnoses, and attendant clinical outcomes among US collegiate athletes returning to organised sports during the SARS-CoV-2 pandemic.

\section{METHODS}

This prospective observational cohort study included National Collegiate Athletic Association institutions who implemented SARS-CoV-2 infection testing and submitted data to the ORCCA Registry. The primary aim of this study was to describe the prevalence and clinical implications of persistent or exertional symptoms on return to 
exercise in athletes following SARS-CoV-2 infection. A detailed description of the ORCCA Registry can be found elsewhere. ${ }^{3}$ For the current study, deidentified data were collected from participating institutions from 1 September 2020 to 1 May 2021 , inclusive of all athletes with prior SARS-CoV-2 infection. Inclusion criteria for this study were: (1) athletes with confirmed SARS-CoV-2 infection by laboratory testing (PCR, antigen or antibody) and (2) reported initial symptom duration or presence of exertional symptoms on return to exercise. SARSCoV-2 testing was performed to screen asymptomatic athletes prior to participation, for surveillance in asymptomatic athletes, and in symptomatic athletes per the discretion of participating institutions. Each participating institution submitted data via a standardised data capture tool and deidentified original clinical reports of the cardiovascular testing performed.

\section{Definitions}

Persistent symptoms were defined as symptoms lasting $>3$ weeks from initial symptom onset. ${ }^{10}$ Exertional cardiopulmonary symptoms were defined as any symptom of chest pain, shortness of breath (SOB), exercise intolerance/fatigue, palpitations/ tachycardia or presyncope/syncope on return to exercise. Initial symptom severity was also prespecified into the following categories: (1) asymptomatic, (2) mild, (3) moderate and (4) cardiopulmonary. Mild symptoms were defined as cough, fatigue, gastrointestinal symptoms (nausea, vomiting and/or diarrhoea), headache, anosmia, ageusia, rhinorrhea, sore throat or nasopharyngeal congestion. Moderate symptoms were defined as the presence of fever, chills, myalgias or COVID-19 toes/fingers. Cardiopulmonary symptoms were defined as chest pain, SOB, palpitations or exercise intolerance. If an athlete had symptoms in multiple categories, they were assigned the most severe category based on their symptoms.

'Triad' testing refers to the combination of 12-lead ECG, troponin and transthoracic echocardiogram (TTE). Abnormal ECGs and TTEs were adjudicated as possibly related to SARSCoV-2 infection using prespecified definitions ${ }^{11}{ }^{12}$ (online supplemental table 1). A troponin measurement was considered abnormal when $>99 \%$ upper limits of normal per the local laboratory commercial assay standards. Advanced diagnostic testing was defined as any of the following (beyond triad testing): cardiac MRI (CMR), cardiac stress testing, cardiopulmonary exercise testing (CPET), chest X-ray, coronary CT angiography, CT-PE protocol, ambulatory Holter/event monitoring or pulmonary function testing.

Abnormal diagnostic testing was defined as any test which led to a diagnosis of SARS-CoV-2-associated sequelae per the clinical assessment performed by participating institutions. SARSCoV-2-associated sequelae were defined as any new cardiac or pulmonary diagnosis reported by the local institution based on diagnostic testing or clinical evaluation.

Definitions for cardiac involvement from SARS-CoV-2 infection were adapted from the Updated Lake Louise Imaging criteria. $^{3}{ }^{13}$ Definite myocardial involvement was defined as: (1) CMR T1 abnormality or late gadolinium enhancement (LGE)+T2 abnormality or (2) CMR T2 abnormality +one or more supportive findings (left ventricular ejection fraction $(\mathrm{LVEF})<45 \%$, small or greater pericardial effusion, pericardial enhancement or troponin $>99 \%$ upper limit of normal). Probable myocardial involvement was defined as: (1) CMR T1 abnormality or presence of LGE+one or more supportive finding (same as definite myocardial involvement). Possible myocardial involvement was defined as: (1) isolated CMR T1 abnormality

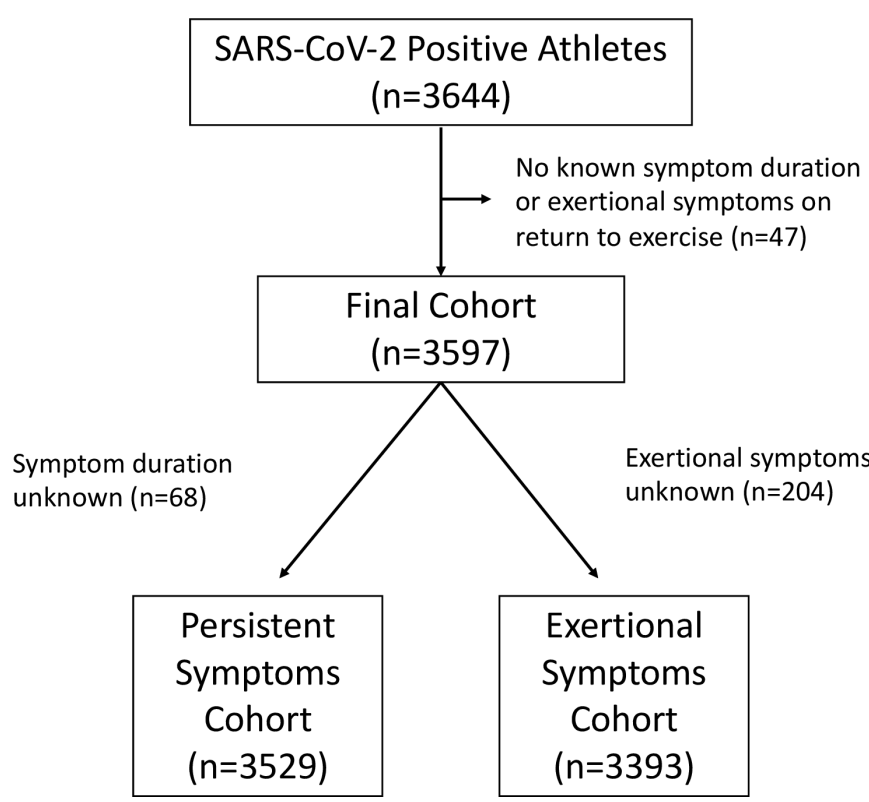

Figure 1 Study cohort and inclusion.

or presence of LGE. SARS-CoV-2 pericardial involvement was defined as a small or greater pericardial effusion or pericardial enhancement on CMR. Any athlete meeting criteria for myocardial involvement of SARS-CoV-2 infection who also had pericardial involvement was labelled as definite, probable or possible myopericardial involvement based on the definitions for myocardial involvement.

For the analysis in this study, only definite or probable cardiac involvement were included as SARS-CoV-2-associated sequelae. Possible cardiac involvement was not considered a relevant sequela given the uncertain relationship of these findings to SARS-CoV-2 infection and unclear prognostic significance. ${ }^{314-16}$

\section{Statistical analysis}

Standard descriptive statistics were used to describe the data. Continuous variables are presented as means and SD or medians and IQR as appropriate, and Student's t-test was used for between group comparisons. Categorical variables are presented as $\mathrm{n}(\%)$ and compared using the $\chi^{2}$ test or Fischer's exact test. Statistical analyses were performed using R: A Language and Environment for Statistical Computing (R Core Team, Vienna, Austria, year 2020, https://www.R-project.org/).

\section{Patient and public involvement}

Patients and the public were not involved in the design, conduct or analysis of this study.

\section{RESULTS}

Among 3644 athletes with SARS-CoV-2 infection submitted to the ORCCA Registry, 3597 (99\%) met study inclusion criteria (figure 1). Baseline characteristics stratified by the presence of persistent symptoms and presence of exertional cardiopulmonary symptoms on return to exercise are presented in table 1 . The total cohort is composed of athletes from 44 colleges/ universities, including athletes representing 26 distinct sporting disciplines.

\section{Persistent symptoms cohort}

Symptom duration was reported in 3529/3597 (98.1\%) of athletes. Persistent symptoms $>3$ weeks from symptom onset 
Table 1 Patientcharacteristics based on the prevalence of persistent or exertional symptoms

\begin{tabular}{|c|c|c|c|}
\hline $\begin{array}{l}\text { Patient } \\
\text { characteristics* }\end{array}$ & $\begin{array}{l}\text { No persistent or } \\
\text { exertional } \\
(n=3424)\end{array}$ & $\begin{array}{l}\text { Persistent } \\
\text { symptoms } \\
(n=44) \dagger\end{array}$ & $\begin{array}{l}\text { Exertional } \\
\text { symptoms } \\
(n=137) \dagger\end{array}$ \\
\hline Female & $1101(32)$ & $16(36)$ & $70(51) \ddagger$ \\
\hline Age, mean (SD) & $20(1)$ & $20(2)$ & $20(1)$ \\
\hline BMI, mean (SD) & $26(5)$ & $26(6)$ & $25(5)$ \\
\hline White-non-Hispanic & $2191(64)$ & $27(61)$ & $83(61)$ \\
\hline Black & $922(27)$ & $13(30)$ & $48(35) \ddagger$ \\
\hline White-Hispanic & $108(3)$ & $1(2)$ & $1(0.7)$ \\
\hline Mixed & $72(2)$ & 0 & $1(0.7)$ \\
\hline Other§ & $87(3)$ & $2(4)$ & $2(1)$ \\
\hline \multicolumn{4}{|l|}{ Pre-existing conditions* } \\
\hline Sickle cell trait & $37(1)$ & 0 & $3(2)$ \\
\hline Diabetes & $11(0.3)$ & $1(2)$ & 0 \\
\hline Hypertension & $18(0.6)$ & $1(2)$ & $1(0.7)$ \\
\hline $\begin{array}{l}\text { Asthma (mild- } \\
\text { intermittent) }\end{array}$ & $329(10)$ & $2(4)$ & $23(17) \ddagger$ \\
\hline $\begin{array}{l}\text { Asthma (mild- } \\
\text { persistent or greater) }\end{array}$ & $69(2)$ & $4(9) \ddagger$ & $10(7) \ddagger$ \\
\hline $\begin{array}{l}\text { Immunosuppressive } \\
\text { agent }\end{array}$ & $6(0.2)$ & 0 & 0 \\
\hline $\begin{array}{l}\text { Obesity }(\mathrm{BMI}>30 \\
\left.\mathrm{kg} / \mathrm{m}^{2}\right)\end{array}$ & $420(12)$ & $8(18)$ & $11(8)$ \\
\hline \multicolumn{4}{|c|}{ Initial symptoms in initially symptomatic patients } \\
\hline Headache & $784(39)$ & $12(32)$ & $44(41)$ \\
\hline Loss of taste/smell & $753(38)$ & $30(79) \ddagger$ & $43(40)$ \\
\hline Nasal congestion & $631(31)$ & $11(29)$ & $20(19) \ddagger$ \\
\hline Sore throat & $629(31)$ & $7(18)$ & $27(25)$ \\
\hline Myalgias & $563(28)$ & $8(21)$ & $26(24)$ \\
\hline Cough & $554(28)$ & $11(29)$ & $39(36)$ \\
\hline Fatigue & $502(25)$ & $15(39)$ & $32(30)$ \\
\hline Fever & $473(24)$ & $8(21)$ & $31(29)$ \\
\hline Chills & $259(13)$ & $3(8)$ & $13(12)$ \\
\hline Shortness of breath & $188(9)$ & $9(24) \ddagger$ & $30(28) \ddagger$ \\
\hline Rhinorrhoea & $170(8)$ & $3(8)$ & $3(3)$ \\
\hline Chest pain & $99(5)$ & $6(16) \ddagger$ & $19(18) \ddagger$ \\
\hline Diarrhoea & $91(5)$ & $3(8)$ & $8(7)$ \\
\hline Other & $87(4)$ & $3(8)$ & $4(4)$ \\
\hline Nausea & $77(4)$ & $2(5)$ & $6(6)$ \\
\hline Vomiting & $32(2)$ & $2(5)$ & $3(3)$ \\
\hline Exercise intolerance & $6(0.3)$ & 0 & $1(0.9)$ \\
\hline Palpitations & $4(0.2)$ & 0 & $1(0.9)$ \\
\hline $\begin{array}{l}\text { COVID-19 toes/ } \\
\text { fingers }\end{array}$ & $2(0.1)$ & 0 & 0 \\
\hline
\end{tabular}

Presented as $n(\%)$ unless noted otherwise.

*Partial data for available for the following characteristics: age $n=3412$ (no persistent or exertional)/n=43 (persistent symptoms), sex 1 patient responded as non-binary in the no persistent or exertional group, BMI $n=3040$ (no persistent or exertional)/ $n=112$ (exertional symptoms), race $n=3380$ (no persistent or exertional)/ $n=43$ (persistent symptoms) $/ n=135$ (exertional symptoms), pre-existing conditions $n=3204$ (no persistent or exertional)/n=136 (exertional symptoms). tThere were eight athletes who were included in both the persistent symptoms group and the exertional symptoms group.

$\ddagger \mathrm{P}<0.05$ compared with the reference group (no persistent or exertional). $\S 0$ ther category includes Asian, American-Indian, Native Hawaiian, Pacific Islander and self-selected other.

१The number of asymptomatic athletes during initial infection for each group was as follows: no persistent or exertional $(n=1056)$, persistent symptoms $(n=0)$, exertional symptoms $(n=18)$. For the remaining patients, initial symptom type was available in the following: no persistent or exertional $(n=2005)$, persistent symptoms ( $n=38)$, exertional symptoms ( $n=108)$.

$\mathrm{BMI}$, body mass index.

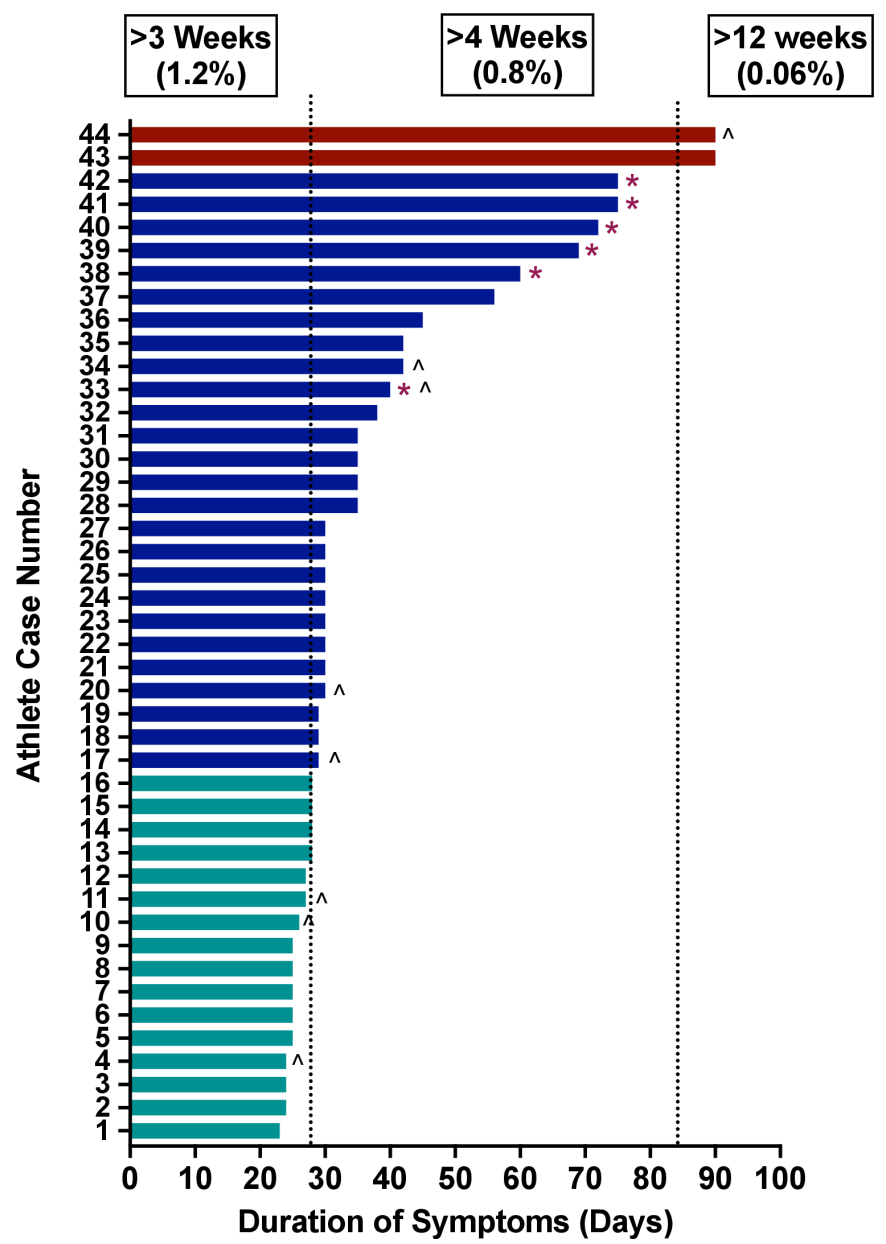

Figure 2 Duration of symptoms for athletes with persistent symptoms. *Denotes athletes with ongoing symptoms on last follow-up. ${ }^{\wedge}$ Denotes athletes with exertional cardiopulmonary symptoms on return to exercise.

were present in $44 / 3529$ (1.2\%). The total symptom duration for each athlete with persistent symptoms is shown in figure 2 . Of the athletes with persistent symptoms, 44 (1.2\%) had symptoms $>3$ weeks, $28(0.8 \%)$ had symptoms $>4$ weeks and 2 $(0.06 \%)$ had symptoms $>12$ weeks. The type of persistent symptom(s) was reported in 40/44 (91\%) athletes. The most common persistent symptom was loss of taste/smell (63\%), followed by SOB (20\%), cough (15\%) and chest pain (15\%) (figure 3A). Twenty-three (58\%) athletes with known persistent symptom type had only isolated loss of taste/smell. There was no difference in the presence of initial moderate or cardiopulmonary symptoms in athletes with and without persistent symptoms (47\% vs 52\%, $\mathrm{p}=0.68$ ). When excluding athletes whose only persistent symptom was isolated loss of taste/smell, there also was no difference in the presence of initial moderate or cardiopulmonary symptoms in athletes with and without persistent symptoms $(69 \%$ vs $52 \%, \mathrm{p}=0.28)$. Similarly, when comparing athletes with initial mild symptoms to those with initial moderate or cardiopulmonary symptoms, there was no significant difference in the development of persistent symptoms (2.0\% vs $1.6 \%$, $\mathrm{p}=0.68)$. No athlete with persistent symptoms had abnormal triad testing (ECG 0/43, troponin 0/43, TTE 0/44). An overview of the advanced diagnostic testing performed for athletes with isolated persistent symptoms is presented in online supplemental figure 1 . 

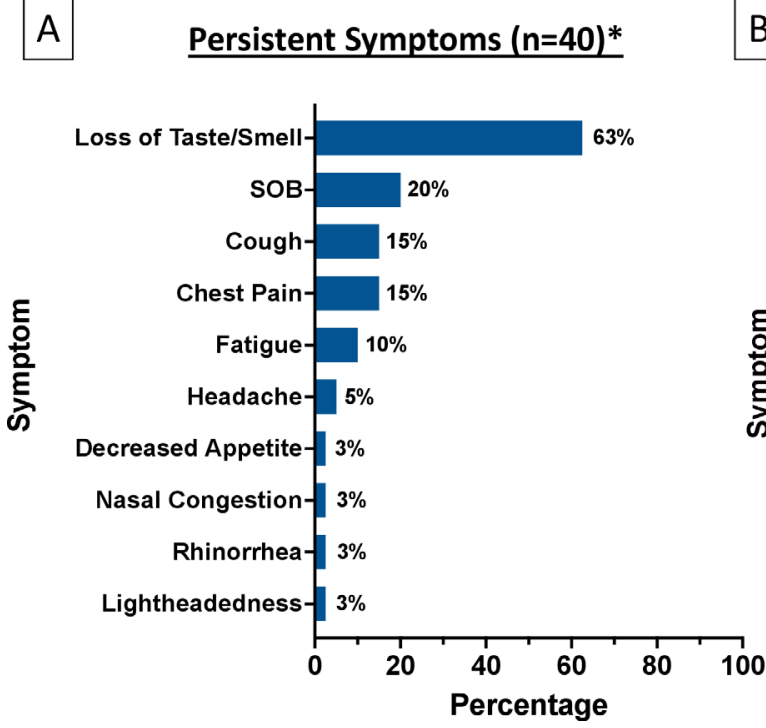

Exertional Symptoms $(\mathrm{n}=137)$

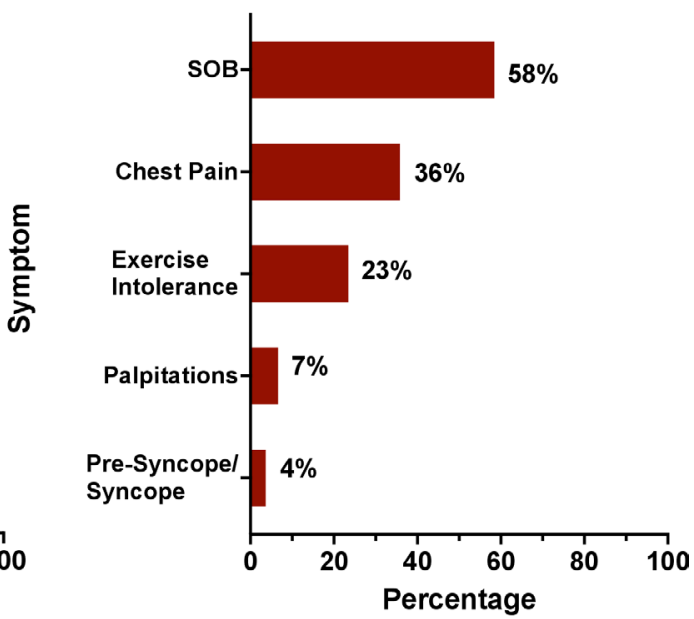

Figure 3 Symptom burden for athletes with persistent symptoms (A) and exertional cardiopulmonary symptoms. On return to exercise (B). *Persistent symptom type available for 40/44 (91\%) athletes. SOB, shortness of breath.

Eight of $44(18 \%)$ athletes with persistent symptoms also had exertional cardiopulmonary symptoms on return to exercise, and diagnostic testing performed in these athletes are included in figure 4 (so each diagnostic test is counted only once). Of these eight athletes with both persistent and exertional symptoms, one athlete received a diagnosis of postural tachycardia syndrome (POTS), and one was diagnosed with pneumonia. No athletes with isolated persistent symptoms without exertional symptoms on return to exercise were diagnosed with SARS-CoV-2associated sequelae.

\section{Exertional Symptoms $(\mathrm{n}=137)$}

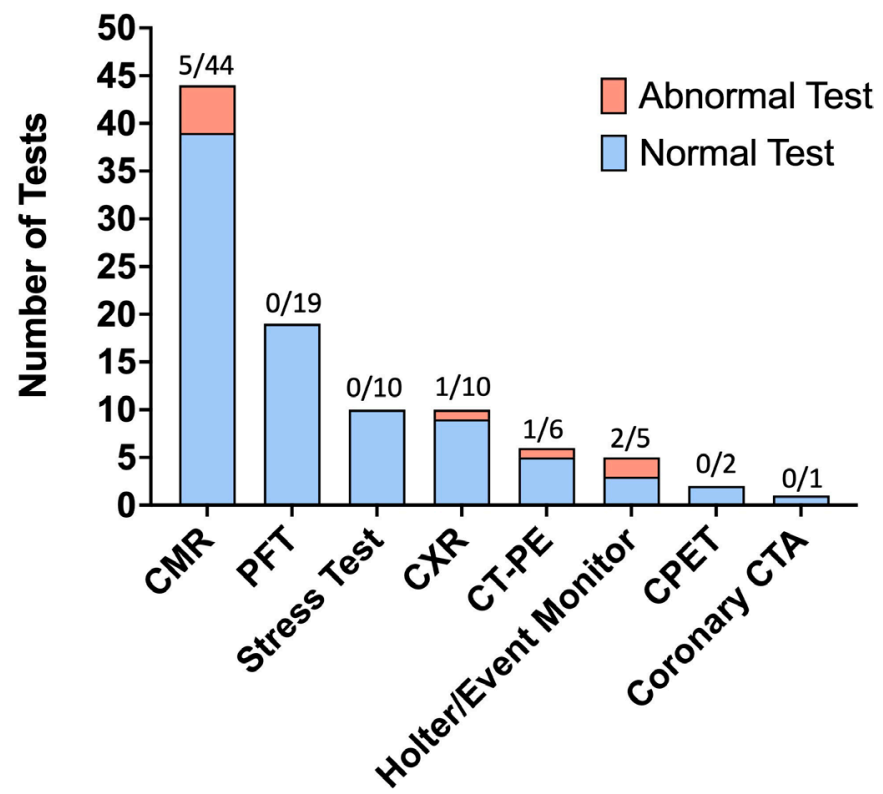

Figure 4 Results from advanced diagnostic testing for athletes with exertional cardiopulmonary symptoms on return to exercise. CMR, cardiac MRI; CPET, cardiopulmonary exercise testing; CTA, CT angiography; CT-PE, CT pulmonary embolism; CXR, chest X-ray.
Exertional cardiopulmonary symptoms cohort

The presence or absence of exertional symptoms on return to exercise was reported in 3393/3597 (94.3\%) athletes. Exertional cardiopulmonary symptoms were present in 137/3393 (4.0\%) athletes on return to exercise. Female and black athletes had a higher proportion of exertional cardiopulmonary symptoms compared with athletes without persistent or exertional symptoms (table 1). Of the athletes with exertional cardiopulmonary symptoms, the most common symptom was SOB (58\%), followed by chest pain (36\%), and exercise intolerance/fatigue (23\%) (figure 3B). The median time from initial infection (symptom onset or positive SARS-CoV-2 test) to return to exercise was 17 days (IQR 13-21).

An overview of the advanced diagnostic testing performed for athletes with exertional symptoms is presented in figure 4. Further clinical evaluation and diagnostic testing led to the diagnosis of SARS-CoV-2-associated sequelae in 12/137 (8.8\%) athletes with exertional symptoms (five cardiac involvement, two pneumonia, two inappropriate sinus tachycardia, two POTS and one pleural effusion) (figure 5, online supplemental figure 2 ). Triad testing was abnormal in 5 athletes with exertional

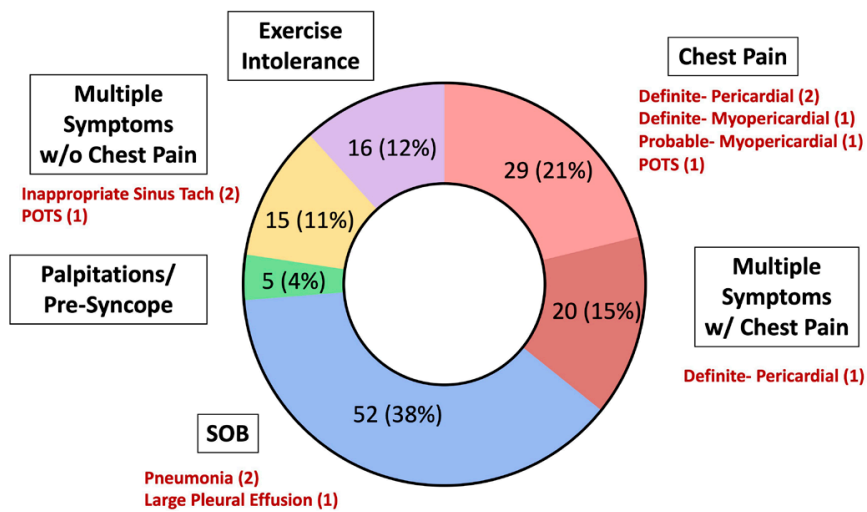

Figure 5 SARS-CoV-2-associated clinical sequelae in athletes with exertional cardiopulmonary symptoms on return to exercise stratified by symptom type. POTS, postural orthostatic tachycardia syndrome; SOB, shortness of breath; w/, with; w/o, without. 
symptoms, including 1/132 (0.8\%) athlete who underwent ECG testing (diffuse $\mathrm{T}$-wave inversions) and 4/117 (3.4\%) athletes who underwent a TTE ( 2 LVEF $<50 \%, 1$ small pericardial effusion, 1 large pleural effusion). Five of 44 (11.4\%) athletes who underwent a CMR for exertional cardiopulmonary symptoms on return to exercise had probable or definite SARS-CoV-2 cardiac involvement, including 3 cases of pericardial involvement, 1 definite case of myopericardial involvement and 1 probable case of myopericardial involvement. One athlete with pneumonia and one athlete with POTS also had persistent symptoms.

The results of CMR testing for SARS-CoV-2 cardiac involvement in athletes with exertional cardiopulmonary symptoms on return to exercise are presented in online supplemental table 2. Of athletes with exertional chest pain who underwent CMR, a total of $5 / 24(20.8 \%)$ had probable or definite cardiac involvement. For athletes with exertional cardiopulmonary symptoms other than chest pain who underwent CMR $(n=20)$, there were no cases of probable or definite SARS-CoV-2 cardiac involvement. The median time from initial infection to CMR was 44 days (IQR 29-70).

\section{DISCUSSION}

We report the prevalence and clinical implications of persistent symptoms or exertional cardiopulmonary symptoms on return to exercise in collegiate athletes following SARS-CoV-2 infection, with the following key findings. First, both the prevalence of persistent symptoms from initial illness (1.2\%) and exertional symptoms on return to exercise $(4.0 \%)$ were low. Second, no diagnosis of SARS-CoV-2-associated sequelae was made following clinical evaluation or advanced diagnostic testing in athletes with only persistent symptoms. However, $8.8 \%$ of athletes with exertional cardiopulmonary symptoms on return to exercise had SARS-CoV-2-associated sequelae. Third, in athletes who had chest pain on return to exercise and underwent CMR $(n=24)$, probable or definite SARS CoV-2 cardiac involvement was found in $20.8 \%$ of cases.

The concern for potential cardiac inflammation and exerciseinduced cardiac events in athletes with SARS-CoV-2 infection resulted in a variety of athlete 'return-to-play' screening guidelines. ${ }^{15} 1718$ These guidelines have undergone several iterations based on evolving clinical experience and published evidence. ${ }^{34}$ The most recent recommendations suggest athletes suffering from asymptomatic or mild infections do not require cardiac testing due to a low incidence of SARS-CoV-2 cardiac involvement, a position further supported by the lack of adverse cardiac events in short-term clinical follow-up. ${ }^{3} 415$ While initial data from the ORCCA Registry found that athletes with cardiopulmonary symptoms, including chest pain and dyspnoea, were at increased risk of SARS-CoV-2 cardiac involvement (OR 3.1, 95\% CI 1.2 to 7.8$),{ }^{3}$ the analysis did not distinguish between the presence of cardiopulmonary symptoms during the acute illness vs those present on return to exercise. Our current study specifically examined the clinical implications of exertional cardiopulmonary symptoms, finding that exertional chest pain on return to exercise presents a potentially high risk (20.8\%) of probable or definite SARS-CoV-2 cardiac involvement. In this cohort, cardiac involvement included the pericardium in all cases, with myocardial involvement found in two athletes. Therefore, a comprehensive cardiac evaluation inclusive of CMR should be considered in athletes presenting with exertional chest pain on return to exercise.

Concern for the effects of postacute COVID-19 symptoms on athletic performance have been reported in several high-profile cases in the media. ${ }^{20}$ Additionally, the prevalences of prolonged symptoms in varying populations of non-athletes with nonsevere COVID-19 illness have been reported in up to $47 \%$ of patients. ${ }^{6-8}$ Our results indicate that persistent symptoms following infection $(1.2 \%)$ or exertional symptoms on return to exercise $(4.0 \%)$ are relatively rare in a large cohort of collegiate athletes, and only $0.06 \%$ of athletes in this study fulfilled the contemporary definition of PACS (symptoms lasting $>12$ weeks) on last follow-up. The percentage of athletes with persistent symptoms other than isolated loss of taste/smell was also very low $(0.6 \%)$. Thus, our findings support that the vast majority of athletes will not be limited by a prolonged illness course or symptoms on return to exercise. While the reasons for a low prevalence of PACS in collegiate athletes were not investigated in this study, we hypothesise that high fitness levels and an otherwise healthy cohort of young competitive athletes may have been protective against the development of persistent symptoms. In a study of 48440 adult patients with COVID-19, higher levels of physical activity were associated with a lower risk of severe COVID-19 outcomes. $^{21}$

\section{Clinical implications}

Findings from this study highlight the importance of continual evaluation and follow-up in athletes returning to exercise following SARS-CoV-2 infection. The presence of exertional cardiopulmonary symptoms on return to exercise, in particular exertional chest pain, warrants clinical evaluation, even in athletes with initial negative cardiac testing after resolution of acute symptoms. As SARS-CoV-2 cardiac involvement is relatively infrequent in young competitive athletes $(0.5 \%-3 \%)^{3-5}$ and adverse cardiac events are rare, ${ }^{34}$ this study provides further support for a symptom-guided cardiac evaluation, including symptoms that present as athletes return to exercise. A comprehensive evaluation, including consideration for CMR, is recommended in athletes with chest pain on return to exercise. A symptom-guided approach to cardiac testing after SARS-CoV-2 infection in athletes is reflected in current expert consensus recommendations. ${ }^{1519}$ While this study suggests that exertional chest pain on return to exercise presents a higher risk for SARS$\mathrm{CoV}-2$ cardiac involvement, it is important not to discount other known clinical signs and symptoms of potential myocarditis. ${ }^{12} 13$

\section{Limitations}

Several important limitations warrant discussion. First, there was no standardised diagnostic workup for athletes with persistent symptoms or exertional cardiopulmonary symptoms on return to exercise, and diagnostic testing was performed at the discretion of the participating institutions. While this represents 'real-world' management of young athletes with SARS-CoV-2 infection, new pathologic diagnoses may have been missed. Second, the higher proportion of exertional cardiopulmonary symptoms in female and black athletes remains of unclear significance and an important area of future work. Third, the results of diagnostic testing were obtained from unblinded clinical interpretation and may have resulted in a degree of observer bias. Unbiased imaging adjudication at a centralised core facility also represents an important area of future investigation. Finally, as athletes diagnosed with SARS-CoV-2 cardiac involvement after initial cardiac testing were restricted from sport prior to a return to exercise, further statistical comparisons regarding the yield of initial cardiac testing vs cardiac testing as a result of exertional symptoms was not possible. 
What are the findings?

- Among 3597 US collegiate athletes with SARS-CoV-2 infection, there was a low prevalence of persistent symptoms $>3$ weeks from initial illness (1.2\%) and a low prevalence of exertional cardiopulmonary symptoms on return to exercise $(4.0 \%)$.

- No athlete with isolated persistent symptoms was diagnosed with SARS-CoV-2-associated clinical sequelae.

- In athletes with exertional chest pain on return to exercise who underwent cardiac MRI $(n=24)$, probable or definite SARS CoV-2 cardiac involvement was found in $20.8 \%$ of cases.

\section{How might it impact on clinical practice in the future?}

- Monitoring athletes for the presence of new cardiopulmonary symptoms as they resume exercise following SARS-CoV-2 infection is important to ensure a safe return to sport.

- The presence of exertional cardiopulmonary symptoms on return to exercise, in particular exertional chest pain, warrants a thorough clinical evaluation, even in athletes with initial negative cardiac testing after SARS-CoV-2 infection.

- Cardiac MRI should be considered in athletes with exertional chest pain after SARS-CoV-2 infection to investigate for cardiac sequalae.

\section{CONCLUSION}

Collegiate athletes with SARS-CoV-2 infection have a low prevalence of persistent and exertional cardiopulmonary symptoms. Exertional cardiopulmonary symptoms on return to exercise, particularly chest pain, convey a higher clinical concern for SARS-CoV-2 cardiac involvement. Thus, a comprehensive symptom-guided evaluation is warranted in athletes with cardiopulmonary symptoms on return to exercise.

\section{Author affiliations}

'Division of Cardiology, Massachusetts General Hospital, Boston, Massachusetts, USA

${ }^{2}$ Cardiovascular Performance Program, Massachusetts General Hospital, Boston, Massachusetts, USA

${ }^{3}$ Department of Orthopedics and Rehabilitation, University of Wisconsin-Madison, Madison, Wisconsin, USA

${ }^{4}$ Division of Cardiology, Duke University School of Medicine, Durham, North Carolina, USA

${ }^{5}$ Department of Family Medicine, Center for Sports Cardiology, University of Washington, Seattle, Washington, USA

Twitter Nathaniel Moulson@NateMoulson_MD, Stephanie A Kliethermes @stephklie2, Timothy W Churchill @TimChurchillMD, Kimberly G Harmon @DrKimHarmon and Jonathan A Drezner @DreznerJon

Acknowledgements The authors are grateful to all the collaborators at the participating institutions and to the Carson, Curran and Dolan families for supporting this work.

Collaborators ORCCA Investigators: Steering Committee: Irfan M. Asif, MD, Aaron L. Baggish, MD, James Borchers, MD, Jonathan A. Drezner, MD, Katherine M. Edenfield, MD, Michael S. Emery, MD, MS, Kyle Goerl, MD, Brian Hainline, MD, Kimberly G. Harmon, MD, Pei-Ni Jone, MD, Jonathan H. Kim, MD, MSc, Stephanie Kliethermes, PhD, William E. Kraus, MD, Rachel Lampert, MD, Matthew Leiszler, MD, Benjamin D. Levine, MD, Matthew W. Martinez, MD, Nathaniel Moulson, MD, Francis G. O'Connor, MD, MPH, Manesh R. Patel, MD, Bradley J. Petek, MD, Dermot Phelan, MD, Lawrence D Rink, MD, Herman A Taylor, MD, MPH.Investigators: Carl Ade, PhD, Aryan Aiyer, MD, Jarrah Alfadhli, MD, Chloe Amaradio, Scott Anderson, ATC, Stephanie Arlis-Mayor, MD, Jonathan S. Aubry, MD, Andrea Austin, MSN, RN
Brenden J. Balcik, MD, Timothy Beaver, MD, Nicolas Benitez, Brant Berkstresser, Thomas M. Best, MD, PhD, Tiffany Bohon, MD, Jonathan P. Bonnet, MD, MPH, Elizabeth Boyington, James Bray, MD, Jenna Bryant, MD, Sean Carnahan, DO, Rachel Chamberlain, MD, Samantha Charters, ATC, Nicholas Chill, MD, Daniel E. Clark, MD, Douglas Comeau, DO, Laura E Cook, MD, Deanna Corey, MD, Amy Costa, MD, Marshall Crowther, MD, Tarun Dalia, MD, Craig Davidson, MD, Kaitlin Davitt, MS, ATC, Annabelle De St. Maurice, MD, MPH, Peter N. Dean, MD, Jeffrey M. Dendy, MD, Katelyn DeZenzo, Courtney Dimitris, Jeanne Doperak, DO, Calvin Duffaut, MD, Craig Fafara, Katherine Fahy, MD, Jason Ferderber, MD, Megan Finn, Frank A. Fish, MD, R. Warne Fitch, MD, Angelo Galante, MD, Todd Gerlt, ATC, Amy Gest, MPA, Carla Gilson, ATC, Jeffrey Goldberger, MD, Joshua Goldman, MD, MBA Erich Groezinger, MS, Jonathan R. Guin, MD, Heather Halseth, Joshua Hare, MD, Beth Harness, ATC, Nicolas Hatamiya, DO, Julie Haylett, RN, MSN, Neal Hazen, MBA, PT, ATC, LAT, Sean G. Hughes, MD, Yeun Hiroi, BS, Amy Hockenbrock, MD, Amanda Honsvall, MD, Jennifer Hopp, MD, Julia Howard, ATC, Samantha Huba, Mustafa Husaini, MD, Lindsay Huston, MD, Calvin Hwang, MD, Laura Irvin, DO, Val Gene Iven, MD, Robert Jones, MD, Donald Joyce, MD, Kristine Karlson, MD, Jeremy Kent, MD, Christian Klein, MD, Chris Klenck, MD, Michele Kirk, MD, Jordan Knight, Laura Knippa, RN, Madeleine Knutson, ATC, Louis E. Kovacs, MD, Yumi Kuscher, Andrea Kussman, MD, Chrissy Landreth, Amy Leu, DO, Dylan Lothian, Maureen Lowery, MD, Andrew Lukjanczuk, MS, ATC, LAT, John M. MacKnight, MD, Lawrence M. Magee, MD, Marja-Liisa Magnuson, DO, MS, Aaron V. Mares, MD, Anne Marquez, Grant McKinley, MD, Scott Meester, MD, Megan Meier, MD, Christopher Miles, MD, Emily Miller, MD, Hannah Miller, MSEd, ATC, LAT, Raul Mitrani, MD, Aaron J. Monseau, MD, Benjamin Moorehead, MD, Robert J Myerburg, MD, Greg Mytyk, ATC, Andrew Narver, DO, Aurelia Nattiv, MD, Laika Nur, MD, Brooke E. Organ, MD, Meredith Pendergast, ATC, Frank A. Pettrone, MD, Jordan Pierce, ATC, Sourav K. Poddar, MD, Diana Priestman, lan Quinn, DO, Fred Reifsteck, MD, Morgan Restivo, James B. Robinson, MD, Ryan Roe, PAC, Thomas Rosamond, MD, Carrie Rubertino Shearer, Diego Riveros, MD, Miguel Rueda, Takamasa Sakamoto, MEd, ATC, Brock Schnebel, MD, Ankit B. Shah, MD, MPH, Alan Shahtaji, DO, Kevin Shannon, MD, Polly Sheridan-Young, PA-C, Jonathon H. Soslow, MD, Siobhan M. Statuta, MD, Mark Stovak, MD, Andrei Tarsici, Kenneth S. Taylor, MD, Kim Terrell, Matt Thomason, ATC, Jason Tso, MD, Daniel Vigil, MD, Francis Wang, MD, Jennifer Winningham, MS, ATC, LAT, Susanna T. Zorn, MD.

Contributors All authors contributed to the study design, data collection, data analysis, manuscript writing and revision. JAD is the guarantor and responsible for the overall content.

Funding This study was funded in part by a grant from the American Medical Society for Sports Medicine (AMSSM) Collaborative Research Network, the AMSSM Foundation, and the Ron Dolan Endowment Fund at the University of Washington. NM is also supported by the University of British Columbia Clinician Investigator Program.

Competing interests JAD is Editor-in-Chief of BJSM and KGH is a Deputy Editor of BJSM. ALB has received funding from the National Institute of Health/ National Heart, Lung, and Blood Institute (NHLBI), the National Football Players Association, and the American Heart Association and receives compensation for his role as team cardiologist from the US Olympic Committee / US Olympic Training Centers, US Soccer, US Rowing, the New England Patriots, the Boston Bruins, the New England Revolution, and Harvard University. KGH has stock options for 98point6 for which she is also on the medical advisory board. MRP is on the Advisory Board for: Amgen, Bayer, Janssen, Heartflow, Medscape, and has research grant funding from NHLBI, Bayer, Janssen, Heartflow, Idorsia. and the Joel Cournette Foundation for research on athlete's hearts.

\section{Patient consent for publication Not applicable.}

Ethics approval All aspects of this study were approved by the Massachusetts General Brigham Institutional Review Board (Protocol \#2020P002667).

Provenance and peer review Not commissioned; externally peer reviewed. Data availability statement Data are available upon reasonable request. Supplemental material This content has been supplied by the author(s). It has not been vetted by BMJ Publishing Group Limited (BMJ) and may not have been peer-reviewed. Any opinions or recommendations discussed are solely those of the author(s) and are not endorsed by BMJ. BMJ disclaims all liability and responsibility arising from any reliance placed on the content. Where the content includes any translated material, BMJ does not warrant the accuracy and reliability of the translations (including but not limited to local regulations, clinical guidelines, terminology, drug names and drug dosages), and is not responsible for any error and/or omissions arising from translation and adaptation or otherwise

Open access This is an open access article distributed in accordance with the Creative Commons Attribution Non Commercial (CC BY-NC 4.0) license, which permits others to distribute, remix, adapt, build upon this work non-commercially, and license their derivative works on different terms, provided the original work is 
properly cited, appropriate credit is given, any changes made indicated, and the use is non-commercial. See: http://creativecommons.org/licenses/by-nc/4.0/.

\section{ORCID iDs}

Bradley J Petek http://orcid.org/0000-0002-6603-2262

Stephanie A Kliethermes http://orcid.org/0000-0001-9756-7406

Kimberly G Harmon http://orcid.org/0000-0002-3670-6609

Jonathan A Drezner http://orcid.org/0000-0003-3519-9120

\section{REFERENCES}

1 Sudre CH, Murray B, Varsavsky T, et al. Attributes and predictors of long COVID. Nat Med 2021;27:626-31.

2 Nalbandian A, Sehgal K, Gupta A, et al. Post-Acute COVID-19 syndrome. Nat Med 2021;27:601-15.

3 Moulson N, Petek BJ, Drezner JA, et al. SARS-CoV-2 cardiac involvement in young competitive athletes. Circulation 2021;144:256-66.

4 Martinez MW, Tucker AM, Bloom OJ, et al. Prevalence of inflammatory heart disease among professional athletes with prior COVID-19 infection who received systematic Return-to-Play cardiac screening. JAMA Cardiol 2021;6:745.

5 Daniels CJ, Rajpal S, Greenshields JT, et al. Prevalence of clinical and subclinical myocarditis in competitive athletes with recent SARS-CoV-2 infection: results from the big ten COVID-19 cardiac registry. JAMA Cardiol 2021;6:1078-87.

6 Havervall S, Rosell A, Phillipson M, et al. Symptoms and functional impairment assessed 8 months after mild COVID-19 among health care workers. JAMA 2021;325:2015.

7 Nehme M, Braillard O, Alcoba G, et al. COVID-19 symptoms: longitudinal evolution and persistence in outpatient settings. Ann Intern Med 2021;174:723-5.

8 Stavem K, Ghanima W, Olsen MK, et al. Persistent symptoms 1.5-6 months after COVID-19 in non-hospitalised subjects: a population-based cohort study. Thorax 2021;76:405-7.

9 Amenta EM, Spallone A, Rodriguez-Barradas MC, et al. Postacute COVID-19: an overview and approach to classification. Open Forum Infect Dis 2020;7:ofaa509.

10 del Rio C, Collins LF, Malani P. Long-Term health consequences of COVID-19. JAMA 2020;324:1723-4
11 Baggish AL, Battle RW, Beaver TA, et al. Recommendations on the use of multimodality cardiovascular imaging in young adult competitive athletes: a report from the American Society of echocardiography in collaboration with the Society of cardiovascular computed tomography and the Society for cardiovascular magnetic resonance. J Am Soc Echocardiogr 2020;33:523-49.

12 Drezner JA, Sharma S, Baggish A, et al. International criteria for electrocardiographic interpretation in athletes: consensus statement. $\mathrm{Br}$ J Sports Med 2017:51:704-31.

13 Ferreira VM, Schulz-Menger J, Holmvang G, et al. Cardiovascular Magnetic Resonance in Nonischemic Myocardial Inflammation: Expert Recommendations. J Am Coll Cardiol 2018;72:3158-76.

14 Clark DE, Parikh A, Dendy JM, et al. COVID-19 myocardial pathology evaluation in athletes with cardiac magnetic resonance (compete CMR). Circulation 2021;143:609-12.

$15 \mathrm{Kim} \mathrm{JH}$, Levine BD, Phelan D, et al. Coronavirus disease 2019 and the athletic heart: emerging perspectives on pathology, risks, and return to play. JAMA Cardiol 2021;6:219-27.

16 Sarma S, Everett BM, Post WS. Cardiac involvement in athletes recovering from COVID-19: a reason for hope. Circulation 2021;144:267-70.

17 Baggish A, Drezner JA, Kim J, et al. Resurgence of sport in the wake of COVID-19: cardiac considerations in competitive athletes. Br J Sports Med 2020;54:1130-1.

18 Wilson MG, Hull JH, Rogers J, et al. Cardiorespiratory considerations for return-to-play in elite athletes after COVID-19 infection: a practical guide for sport and exercise medicine physicians. Br J Sports Med 2020;54:1157-61.

19 American Medical Society for Sports Medicine and the American College of Cardiology. Cardiac considerations for College Student-Athletes during the COVID-19 pandemic. Available: https://www.amssm.org/Content/pdf-files/COVID19/NCAA COVID-18-AUG-2021.pdf [Accessed October 27, 2021].

20 Lee M. Slowed and sidelined, some athletes struggle to return from long-haul covid. Available: https://www.washingtonpost.com/sports/2021/04/19/athletes-long-haulcovid-justin-foster/ [Accessed 19 Apr 2021].

21 Sallis R, Young DR, Tartof SY, et al. Physical inactivity is associated with a higher risk for severe COVID-19 outcomes: a study in 48440 adult patients. Br J Sports Med 2021;55:1099-105. 